\title{
Future Application Architecture for the Pharmaceutical Industry
}

\author{
Thomas Huber, Rainer Alt, Vladimir Barak, Hubert Österle \\ Institute for Information Management \\ University of St. Gallen \\ Müller-Friedberg-Str. 8 \\ 9000 St. Gallen, Switzerland \\ E-mail \{Prename.Surname\}@unisg.ch
}




\section{Introduction - New Business Models Are Emerging}

Profound changes are taking place in the way business is being done in the information age. An excellent example is provided by Cisco, the leading supplier of Internet-equipment, such as routers, switches and the like. Sales amounting to some USD 8 billion. highlight that only few companies have better understood the far-reaching management consequences of new technologies than Cisco. The company has been in the front line whenever it came to transforming management practices through the use of the new technologies. Cisco is thoroughly organized as a network. Existing and prospective customers, suppliers, other business partners and employees are tightly interlinked. This year, Cisco expects to sell products for more than USD 5 billion (more than half of its total sales) via the Internet. Cisco's Business Networking solution links the systems of suppliers, contract manufacturers and assemblers to Cisco's production processes. To the outside world, i.e. to customers, Cisco appears as a single enterprise. Through the Cisco Intranet, the contract partners directly process the orders placed by Cisco's customers and deliver the selection of items ordered directly to the buyer, frequently without Cisco seeing the items at all. Outsourcing of $70 \%$ of production has enabled Cisco to boost its sales four times without the need for additional facilities and, on top of this, Cisco has succeeded in shortening the time to market for new products by two thirds. At the same time, seven out of ten customer requests for technical assistance are dealt with electronically; and this at high degrees of customer satisfaction. The consistent utilization of the network for its after-sales service has made it possible for Cisco to save more money than its biggest competitor spends on research and development [cf. Byrne 1998].

The Cisco example clearly shows that the economy is in the process of radical change (e.g. [Naisbitt 1994], [Laszlo 1997], [Byrne 1998). Today, the environment of international companies is marked by globalization and individualization of products and services, specializing and networking of companies, more complex technologies, shorter product life cycles and increased competition in many industries. In face of these developments it is no longer sufficient for companies to pursue a policy of small steps to improve their performance in the areas of critical success factors, such as quality, costs and speed. Instead achieving repeated quantum leaps is the challenge. Furthermore, the ongoing reduction in vertical integration and concentration on core competencies have led to a higher degree of international division of labor. ${ }^{1}$ Cooperations and strategic alliances are being formed which call for enhanced inter-enterprise coordination of processes [cf. Fleisch/Österle 2000].

1 An explanation provides the theory of comparative cost advantages [cf. Porter 1992] or for greater detail [cf. Caves et al. 1990] 
On the one hand, these general economic developments dictate the requirements to be addressed by the technological infrastructure of enterprises while, on the other hand, it takes the developments in the technology landscape to make them possible. It is primarily the developments in the fields of information and communication technologies that are not only changing the way business is being done but are also causing paradigm shifts in the organization. They are ultimately transforming the industrial society into the information society [cf. Österle 1995] (see Figure 1).

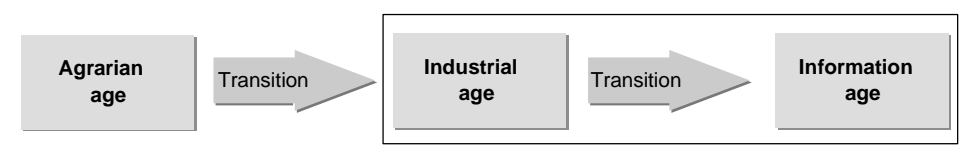

Figure 1: Eras of Change

\section{From Business Model to Application Architecture}

"The bridge to the $21^{\text {st }}$ century is under construction, and the only way we're going to be able to build it quickly and correctly is if we understand the technological challenges ahead of us " [Millett 1997].

The development of a future application architecture presupposes an understanding of the future business models [cf. Österle 2000]. A certain vision of future strategies and processes is critical to identify the systems which support those processes. Conversely, it takes an analysis of current trends in the areas of management and technology for a vision of future business models to be obtained (see Figure 1).

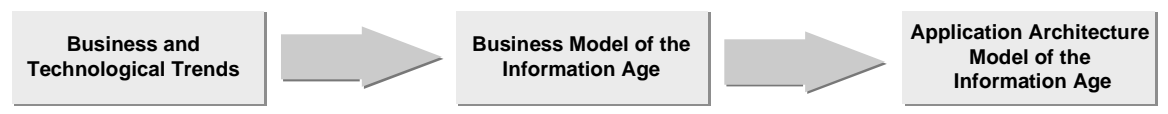

Figure 1:Trends Leading to the Application Architecture

Since some of the central business and management trends (e.g. globalization, specialization, virtualization) have already been mentioned earlier, this paper focuses on developing an application architecture for the information age. This architecture represents an implementation of the business model of the information age at the IS/IT level. In the following the architecture will be elaborated and illustrated with the technological trends and examples which are especially relevant to the pharmaceutical industry. 


\section{Future Business in the Pharmaceutical Industry}

There is little doubt that the trends described above will fundamentally change business processes, rules and players. Specific, high-impact factors for the pharmaceutical industry are:

- Globalization respectively regionalization of certain business processes ${ }^{2}$,

- Cost pressure from government authorities (health care authorities),

- Time and cost-intensive development processes with shorter product life cycles,

- Shifting of selling and marketing activities from bulk buyers and hospitals to the medical practitioners and even the individual patients, and

- Concentration and optimization of manufacturing and administration processes.

On their way to the information age, companies will have to radically review their value proposition, strategic positioning, and organization. An industry-specific business model facilitates these activities [cf. Österle 2000]:

1. Business Networking. "Inter-corporate networks and inter-corporate computing are fundamentally changing worldwide patterns of commerce" [Martin 1997]. As discussed earlier in the introductory chapter, many of the current developments in the economy and in management are pointing towards a higher degree of networking between enterprises. Since these developments are IT enabled, Business Networking forms the first and decisive pillar in the business model of the information age on which the other six aspects are more or less directly built on. Added to this is the fact that pharmaceutical companies are devoting more attention to identifying their role in a networked economy (e.g. in the areas of $\mathrm{R} \& \mathrm{D}$, production or distribution) and that the information systems or rather the application architecture of these enterprises will be implemented by such components as APS/SCM and electronic commerce.

2. Customer process support. The alignment of internal to customer processes has various consequences for a pharmaceutical company. Its ultimate customer, for instance, may not just want to buy some medicine but may look to it for full coverage of his or her health process. This would include diagnosis, treatment, advice, alternatives, insurance etc. If possible, he or she would prefer to have all these services from a single source. Obviously, we are at pre-

2 Globalization, e.g. in the areas of finance, controlling, planning and R\&D processes, and, partly, the production processes; regionalization, e.g. in the areas of selling and distribution processes and some certain production processes. 
sent still far from being able to offer such a service. But as far as the comparability and the ordering of medicines are concerned, there are indeed a first few online pharmacies engaged in this business sector. A typical example is PlanetRx [www.planetrx.com]. Aside from providing the possibility of comparing and ordering medicines online (including medicines obtainable on prescription), vitamins, health food or medicinal appliances, the company`s offering also includes advice and the latest health information. The customer centricity concept will in the future application architecture be represented by the component CRM or SFA.

3. Knowledge management. Knowledge management is one of the most important factors in the R\&D area of pharmaceutical companies. Pfizer Inc. (Viagra), for instance, has had all its R\&D documents digitalized and, incidentally, is sending these also electronically to the food \& drug administration (FDA) which in the USA has to approve all medicines. In the past, this involved the submittal of large amounts of paper and whenever questions were raised on the part of the FDA, it was necessary to sift through piles of paperwork by hand. Today, Pfizer uses Internet technologies in this area and has been able to cut the time for the approval process by half [cf. Hamm/Stepanek 1999]. A separate component is envisaged in the future application architecture to support knowledge management.

4. Electronic services. Companies will have to decide which Business Networking processes they intend to handle internally and which will be procured on the market. According to Chapter 2, we will refer to the latter as electronic services (eServices). An example of an already existing eService in the health sector is ShareNet [www.sharenet.org] which operates an EDI platform for the processing of electronic transactions (exchange of patient data, billings, etc.). The clearing center service lets participating companies exchange information without having to implement individual EDI links between themselves. Since eServices are sourced from the market, they are not included in the future application architecture. Nevertheless, they are an important element of the future business model.

5. Smart appliances. In the area of the intelligent appliances, mobile phones, electronic agenda, Internet, TV, etc. are rapidly merging. These technologies inherit multiple potentials, for example, a patient to could be told electronically to take his or her medicine, and infrared interfaces could be used to transmit pulse beat, blood pressure, etc. Diagnosis instruments could be connected via the Internet with provider systems and a patient could have the necessary medicines delivered as required. The intelligent home concept refers to the developments in the private homes and would not be found directly in the future application architecture of the enterprises. However, enterprises would have to be prepared to communicate with their customers through different channels. 
6. Enterprise resource planning. Contrary to previous business process reengineering approaches, reengineering in the business model of the information age differs as the challenge is to (re)design complete networks rather than internal processes. Online, realtime, integration of customers, suppliers and external service providers are the key words which are relevant in this context. Tough competition continues to force companies in many industries to optimize their internal business processes. To this end, ERP systems will continue to be used in the future. Therefore, they form an important component in the future application architecture, too. Apart from the classical ERP systems, there are two other components which will be increasingly resorted to in order to improve processes: data warehouses and Master Data Management applications. The former concentrate on consolidating data from the different mostly heterogeneous - ERP systems. The latter contain the key data of all parts of the enterprise will be and contribute to vital standardization in business processes. An important consequence will be the streamlining of communications among internal ERP systems.

\subsection{Elements of the Business Model}

In the business model of the information age, information, services and products are systematically sourced from external partners. Existing and, above all, emerging communication media (e.g. e-mail, phone, message, video, EDI, receipt, net operation, chat room services) and market services (e.g. information, news, payment, directory, master data, public key, broker services) will support both the internal and external processes. The entirety of these services may be reduced to the mental construct of a 'business bus' (see Figure 1) [cf. Ranadivé 1999].

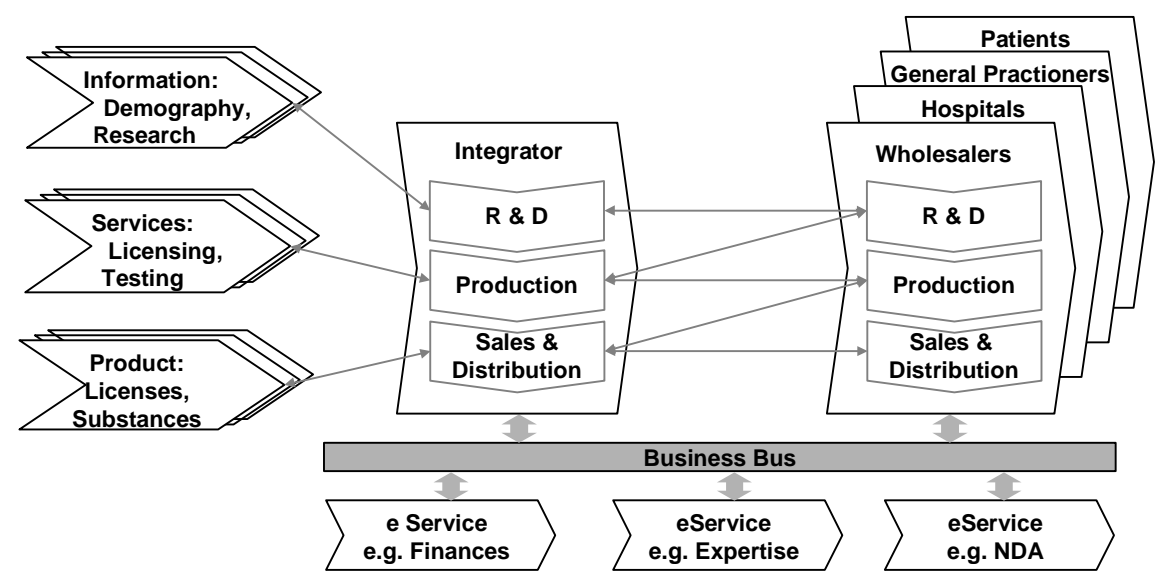

Figure 1: New Business Model for the Pharmaceutical Industry 
Figure 1 shows the business model of the information age as applied to the pharmaceutical industry. Despite a great variety of information, services and products are obtained from outside partners, the pharmaceutical companies are still relying on a (horizontally) very wide basis. From R\&D through procurement, warehouse management and production to marketing and sales, many activities are still sited in-house. Table 1 depicts areas where pharmaceutical companies are already linked-up with outside partners.

\begin{tabular}{|c|c|}
\hline Area & Relations to/for \\
\hline Research & $\begin{array}{l}\text { - In-licensing: licenses/patents on substances from outside re- } \\
\text { search partners } \\
\text { - Information services } \\
\text { - Cooperations with research partners } \\
\text { - Inter-divisional networks for new products }\end{array}$ \\
\hline Development & $\begin{array}{l}\text { - In-licensing: licenses for products from outside research } \\
\text { - } \\
\text { - } \\
\text { - } \\
\text { - } \\
\text { - Rinirtual Comers } \\
\text { - } \\
\text { Expertise network }\end{array}$ \\
\hline Marketing & $\begin{array}{l}\text { - } \\
\text { - } \\
\text { - } \\
\text { Curchase of information (competitors/demography) } \\
\text { general practitioners) } \\
\text { - } \quad \text { Electronic commerce (Internet presence) }\end{array}$ \\
\hline $\begin{array}{l}\text { Production \& } \\
\text { distribution }\end{array}$ & $\begin{array}{ll}\text { - } & \text { Outsourcing of certain process steps } \\
\text { - } & \text { Suppliers network (for production components) }\end{array}$ \\
\hline Finance & $\begin{array}{ll} & \text { Regional shared services } \\
\text { - } & \text { Relations with finance service providers }\end{array}$ \\
\hline
\end{tabular}

Table 1: Business Networking Relations in the Pharmaceutical Industry

One of the questions arising relates, for instance, to what role the companies will be playing within a future health-care network. The companies may perfectly well operate in central role within such a network. They may act as the vendor of the health care process (i.e. operate as a clearing center in the health-care process as shown in Figure 2). Such strategic decisions will directly influence the application architecture of the enterprises, since the information systems act as the central enablers for such networks. 

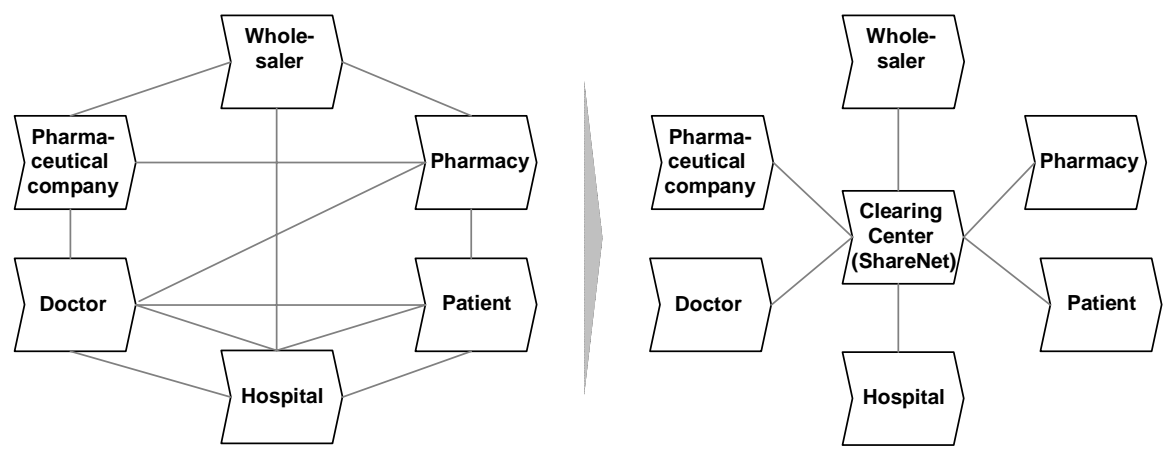

Figure 2: Clearing Centers in the Pharmaceutical Landscape

\section{Application Architecture of the Information Age}

Webster's Dictionary defines architecture as the art or science of building. Indeed, developing an application architecture is some form of art since trends in the extremely fast-moving IT industry are extremely hard to anticipate. However, this is definition is of little use in our context. Therefore, the following definition of application architecture [cf. Tibbetts 1995] has been adopted:

Definition: Application architecture describes the individual technical components (application types) of a corporate information system as well as the relations (interfaces) between these components.

In the first place, an application architecture for the information age has to meet the challenges emerging from the business model of the information age. For example, companies, such as Wal-Mart or Amazon.com, have succeeded in strengthening their competitiveness significantly by managing the flow of goods and information through all stages of the value-added process. The management of these relations forms the core of Business Networking which comprises the optimization of planning, implementation and monitoring of the value-added processes beyond corporate boundaries as well as the increasing customer-orientation. Both efficiency and effectiveness of Business Networking are determined by the degree to which information (e.g. on required planning data, orders, controlling information, etc.) is accessible in the whole network of partners. The Business Networking capabilities of existing systems still have to be enhanced and a number of standard software applications are available which better meet these requirements than classical ERP systems. Examples are advanced planning and scheduling systems (APS), customer relationship management systems and electronic commerce applications. Some of these have been brought on the market by the established ERP vendors (e.g. SAP's Advanced Planning and Optimization - 
APO - module), others by newcomers that have not been present on the ERP market (e.g. i2, Manugistics, Siebel or Harbinger). The main questions which emerge for designing the new application architecture are:

- Which requirements have future application architectures to meet?

- What applications support internal and interorganizational processes?

- How can new applications be integrated into existing architectures?

Two factors that future application architectures have to meet follow from the discussions in the preceding chapters. These are: flexibility, networking, and standardization [cf. Sinz 1997].

\begin{tabular}{|c|c|}
\hline $\begin{array}{l}\text { Marks of Quality } \\
\text { for Application } \\
\text { Architectures: }\end{array}$ & $\begin{array}{l}\text { Marks of Quality for } \\
\text { Information System } \\
\text { Architectures } \\
\text { [Sinz 1997]: }\end{array}$ \\
\hline $\begin{array}{l}\text { - Flexibility } \\
\text { - Networking } \\
\text { - Standardization }\end{array}$ & $\begin{array}{l}\text { - Adaptability } \\
\text { - Reusability } \\
\text { - Standardization }\end{array}$ \\
\hline
\end{tabular}

Figure 1: Marks of Quality for Application Architectures

\subsection{Flexibility}

A necessary feature of an application architecture of the information age is its flexibility to adapt itself to constantly and rapidly changing environmental conditions. Relevant environmental conditions are:

- Changes in the processes. Globalization and specialization of enterprises are ongoing processes. News about mergers and acquisitions, joint ventures or outsourcing continue to make the headlines in the business press. There are no signs of consolidation in the foreseeable future. Therefore, it is crucial that application architectures should define corporate information systems in a way to render them capable of supporting constantly changing processes.

- Changes in the IS/IT domain. The rapid technological developments in the field of the information and communication technologies are only very difficult to predict. On the one hand, the definition of the architecture should be sufficiently precise to serve as a blueprint for an enterprise but, on the other hand, it should be open enough to permit any future IT developments to be taken advantage of. 
A major benefit of flexible application architectures is the improved coordination of disparate current and upcoming IT projects. In this process, the architecture blueprint establishes a set of principles for the IT projects [cf. Metagroup 1998]. In addition, such a set of principles permits an evaluation of the individual projects for their importance in realizing the planned architecture.

\subsection{Networking - Capability of Integration}

Both the specialization and the globalization of enterprises call for a higher degree of networking between the companies and their customers and suppliers. This is why high levels of networkability are necessary in the information age. For instance, Heineken (USA) stated that its new SCM system has halved delivery times. Instead of having a Heineken salesman call, big distributors now log on Heineken`s system to update their planning data online [cf. Stein 1997]. The key to realizing modern forms of cooperation is in the integration of information flows along a supply chain. An efficient cooperation calls for processes that are automated to a maximum extent. However, automated coordination of processes is possible only if the systems supporting these processes are highly integrated with internal integration forming the basis for external integration. A requirement of highly integrated (internal) systems is for standardization of business objects. At a technical level, message-based solutions have been variously recommended (cf. [Jonsson 1998], [Metagroup 1997]) to connect information systems. Clearly, a change is occuring from the classical EDI messaging types, such as EDIFACT or STEP and proprietary networks (WAN, LAN), towards the more flexible Internetstandards (e.g. XML).

\subsection{Standardization}

As described in Chapter 2, standards significantly reduce the coordination needs between trading partners and, at the same time, provide the basis for integrated information flows. Internet standards, such as HTML, SMTP or TCP/IP, have been important enablers for the development of electronic commerce. Only the availability of these general accepted, formal specifications for communication between heterogeneous information systems has permitted the efficient integration of the information flows between suppliers, producers, customers and supporting service providers. Standardization facilitates the transfer of information between the individual system elements of corporate information systems. From an economic perspective, standardization leads to reduced information costs and enhanced information value. However, full standardization of the system elements would restrict heterogeneity and, consequently, might result in a less than opti- 
mum support for the user. In other words, pervasive standardization would entail opportunity costs resulting from sub-optimal support of the users (or processes) [cf. Buxmann 1996].

\section{Components of the Application Architecture}

\subsection{Future Application Architecture Areas}

Based on a number of workshops the following 22 basic areas have been identified which reflect the activities which have to be supported in multi-national companies. These activities are always important, even though individual applications and the distribution of these applications among business partners and systems are subject to change. The areas are:

- Development. Applications and services supporting the development process, e.g. CAD, product data management applications and graphic design tools.

- Research. Applications and services supporting the research process, e.g. $\mathrm{CAD}$, graphic design tools and statistical applications.

- Demand planning. Applications and services permitting an as accurate as possible planning of customer demand, e.g. SAP`s i2 or APO.

- Requirements planning. Applications and services permitting supply planning, e.g. SAP's APO.

- Production planning. Applications and services supporting production planning, e.g. ERP systems.

- Procurement management. Applications and services to manage the procurement of materials for production processes, e.g. ERP systems.

- Inventory management. Applications and services supporting materials management, e.g. SAP's R/3 module for materials management (MM).

- Production. Applications and services supporting the production processes, e.g. SAP's R/3 production planning module (PP).

- Distribution / transport. Applications and services to handle distribution and transport, e.g. parts of SAP's R/3 sales and distribution module (SD).

- After-sales service. Applications and services for after-sales processes.

- Human resources. Applications and services supporting the management of personnel data. 
- Payroll accounting. Applications and services to process payroll accounts, e.g. payroll services provided by ADP.

- Accounts payable administration. Applications and services for the administration of accounts payable.

- Accounts receivable administration. Applications and services for the administration of accounts receivable.

- Internal/external financial accounting. Applications and services to handle the internal and external financial accounting, e.g. SAP's R/3 FI module.

- Desktop purchasing. Applications and services permitting individual employees to order indirect articles on their own initiative.

- Sales. Applications and services to handle sales processes, e.g. SD modules.

- Executive information. Executive information systems (EIS) concentrate on the graphical processing and manipulation of data, e.g. Seagate's HOLOS.

- Groupware. Applications and services, such as Lotus Notes or Microsoft`s Outlook.

- Document management. Applications and services for the management of documents in different formats and distributed environments

- Data standardization. Applications and services for the standardization of master data for customers, products, materials or accounts.

- Data collections. Data warehouse applications and services, e.g. SAP's Business Warehouse.

The consistent use of the terminology, applications or services is intended to suggest that, in the future, many of these areas need not necessarily be covered by a company's own applications and that the functionality required can be bought from a service provider instead.

\section{2 'Extended' Make-or-Buy Decision}

For each of the application areas identified above, a company will have to make two decisions. First of all, it will have to decide whether it wants to build the necessary applications in-house (make) or rather employ a vendor to supply the required functionality as a service (buy). The second decision is on whether it wants to have the functionality standardized on a corporate level or allow decentralized decisions from the individual divisions. Standardization in this context relates both to the processes and the data (especially the master data) that are to be adopted (see Figure 1). There are no hard and fast rules and a company`s decision will 
essentially depend on its strategic concepts in designing its own processes and positioning them in a network.

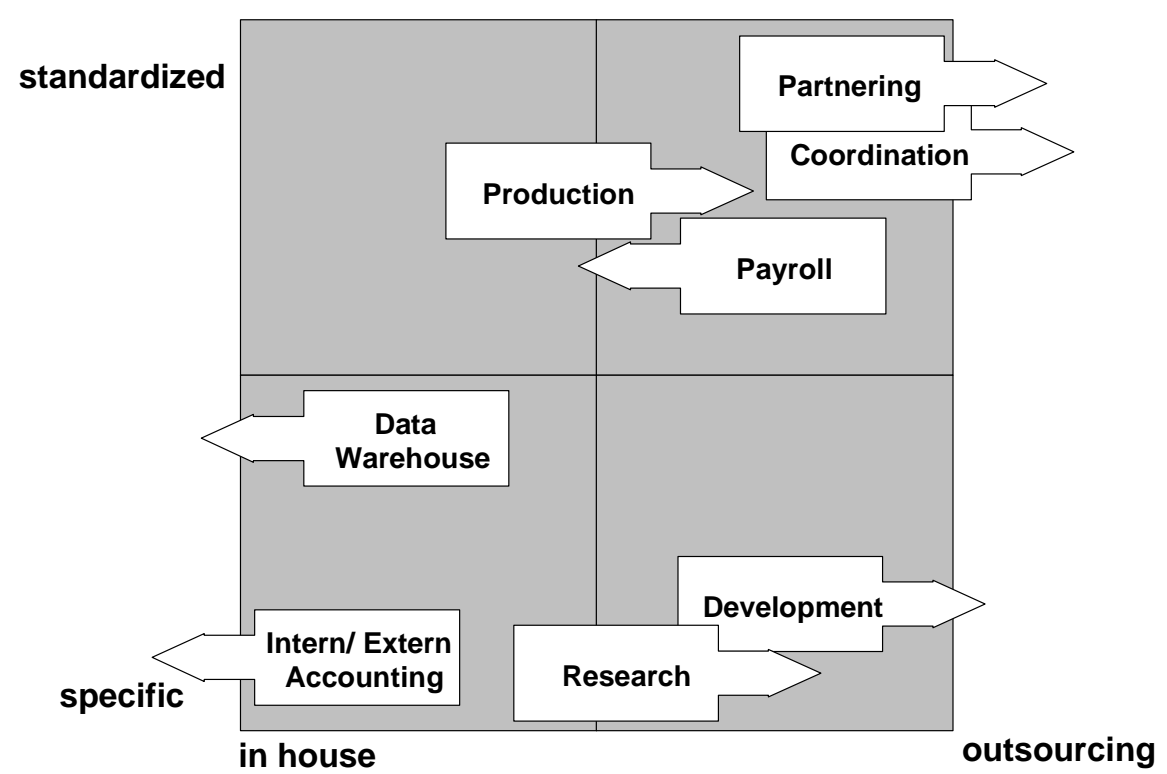

Figure 1: Example for 'Extended' Make-or-Buy Decision

Nowadays it is already possible for enterprises to buy quite a number of services from external providers. Table 1 shows a list of such services with individual services being enumerated in the rows of the table. Listed in the columns of the table are the 22 application architecture areas. This permits the services to be related to the individual application architecture areas (gray fields). These relations provide guidance in identifying the possible uses of the services. The ultimate combination can only be decided individually for each situation. 


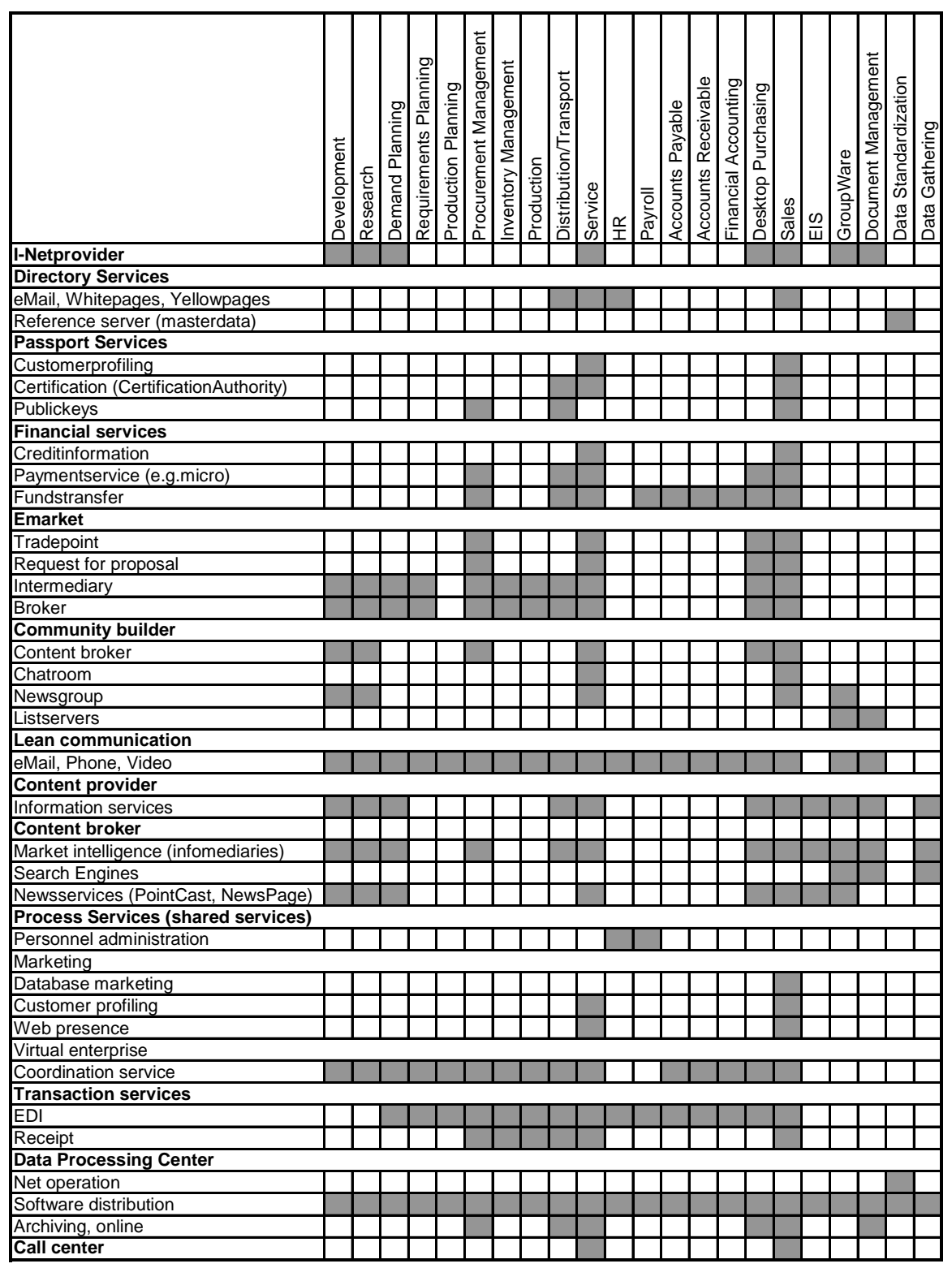

Table 1: Services for Application Architecture Areas 


\subsection{Application Architecture Components}

From the workshop discussions eight application components were defined which build on the 22 application areas. These application architecture components will have to be included in the planning of future architectures (see Figure 2). ${ }^{3}$ The components include applications for master data management, classical ERP systems, data warehouse applications, advanced planning and scheduling applications (APS) for an integrated supply chain management (these may also be described as DSS - decision support systems), electronic commerce applications, customer relationship management (CRM), applications for knowledge management and finally EIS - executive information systems. All these applications are based on data and process standards which the individual companies will have to define.

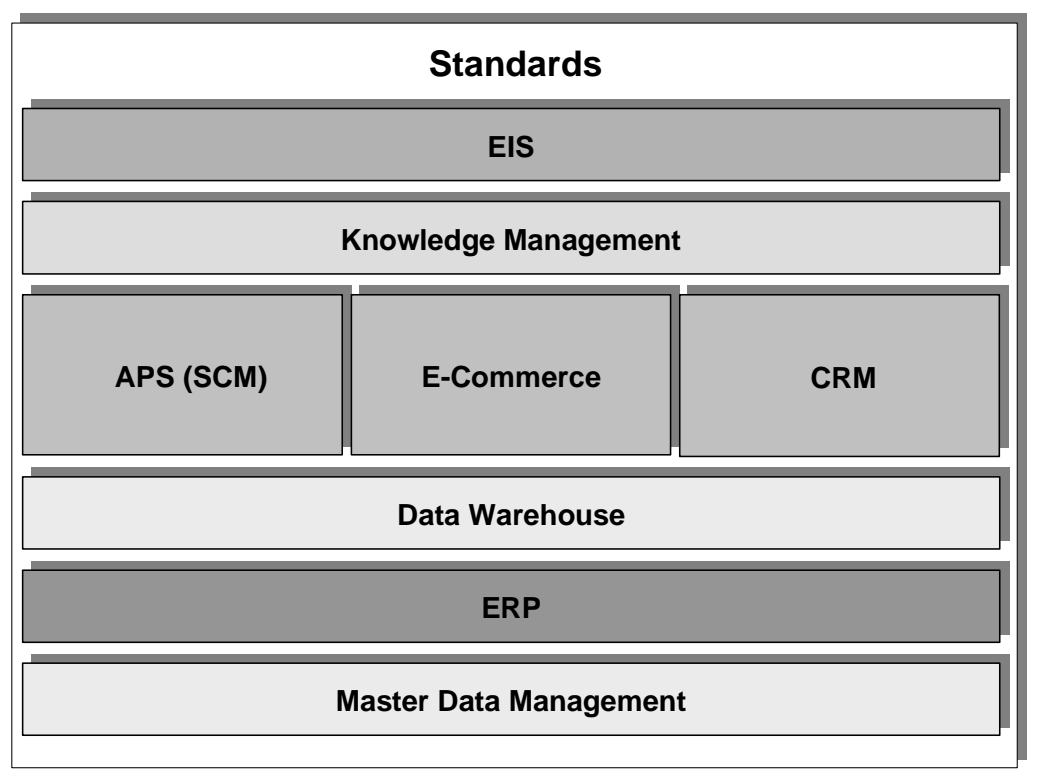

Figure 2: Application Architecture Components

The following table (Table 2) shows how the architecture areas and components can be related. It helps in determining and clarifying what functionality application components include and to identify overlaps.

3 Generally speaking, specialized applications might be used for all 22 application areas. However, with a view to minimizing the interfacing effort and a consistent integration of the applications, it would not make sense to use different applications for all areas. 


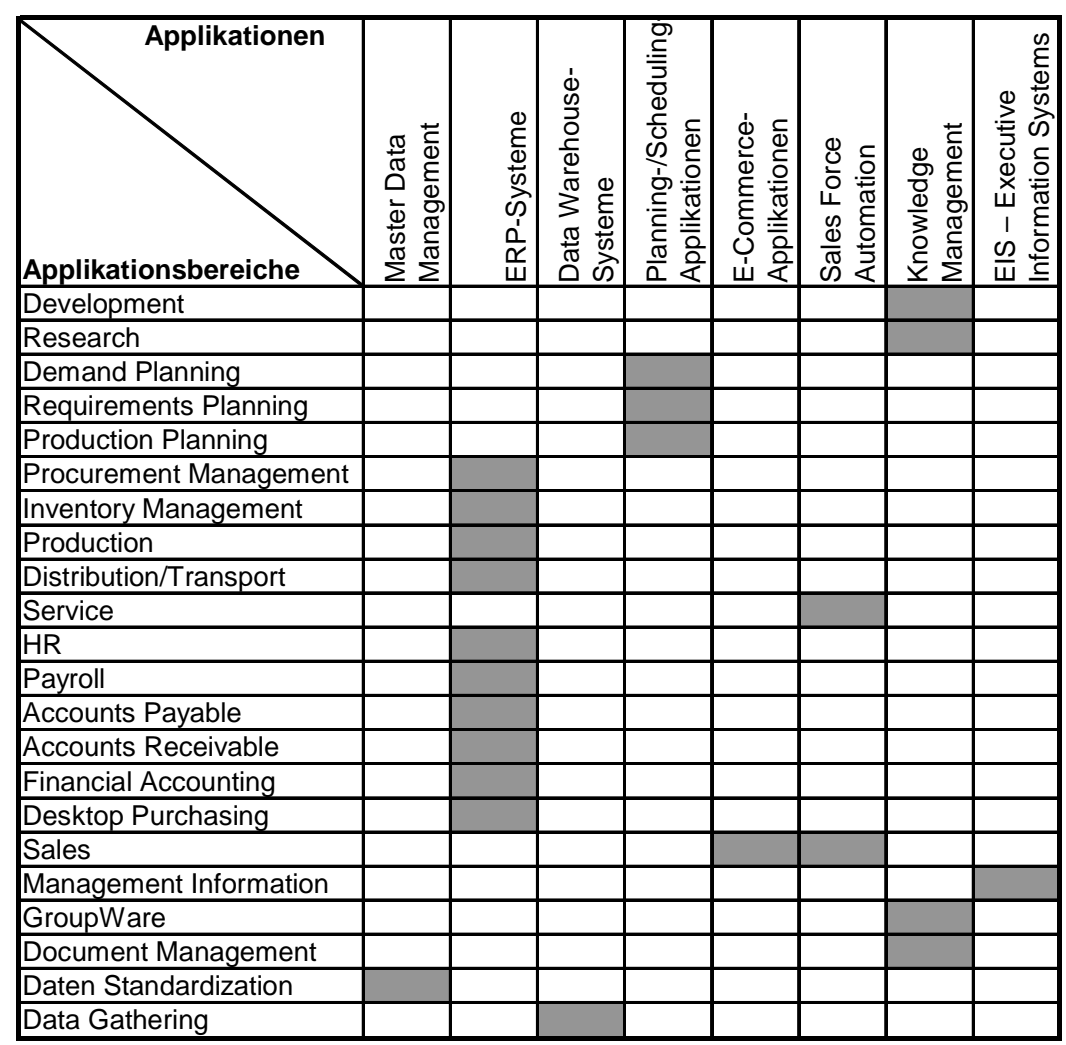

Table 2: Combination of Architecture Areas and Components

The application architecture components will be described in greater detail in the following paragraphs.

- Master data management. The standardization of processes and data is a prerequisite for the integration of heterogeneous applications (see Chap. 4.1.3). Whereas the standardization of processes is effected mainly by guidelines (also called business rules) in the form of written documentations, an automated approach would be required for master data. In future, enterprises will be using an increasing number of specialized applications that are designed only to create and distribute master data.

- ERP systems. ERP systems will continue to form the core of corporate application architectures. These ERPs are required to be closely integrated with the APS, electronic commerce and SFA applications in order to fulfil the requirements of Business Networking. Especially in the fields of payroll accounting, inventory management, transport and accounts payable administration, there are service offerings on the market. ADP, for instance, is a leading 
provider in the field of payroll accounting and handles payroll accounts for approx. 20 million employees in the US.

- Data warehouse applications. Data warehouse applications provide decision makers with a consistent data base. The relevant data from the various (heterogeneous) productive systems are collected and processed for analysis. While the employees in production, sales, bookkeeping, etc. use the operative systems, those individuals who deal with the analysis of the data (e.g. controllers) can draw on the data accumulated in the data warehouse. This approach ensures that these analyses which place an enormous load on computer capacity will not impair the operative work.

- Advanced planning and scheduling applications. In the last decade, process optimizations in production have brought about mass customization, efficient customer response programs (ECR) and vendor-managed inventories (VMI). Each of these challenges boils down to more goods to be planned with reduced lot sizes. This has moved the supply chains of the enterprises into the focus of attention [cf. Bermudez/Girard 97]. Shorter supply chain cycle times and a shrinkage of inventories have become the main targets. These targets can be achieved only if all enterprises along a supply chain cooperate and, for instance, agree to release their planning data to their upstream suppliers. Standard applications have come on the market during the last two or three years to support integrated planning (e.g. SAP`s APO, i2 or Manugistics).

- Electronic commerce applications. Electronic commerce applications provide catalogues and ordering facilities for customers. Being mostly Internet-based, electronic commerce applications have provided new interaction channels with existing customers and have been successfully used to reach new customers. This is combined with significant cost reductions and time advantages in the area of the sales processes.

- Customer relationship management applications. Customer relationship management applications have emerged in various industries. These applications provide functions for after-sales service, marketing and sales, help desk, call centers, market research and for the interaction with the customers through the Internet. Among leading vendors of such systems are Siebel and Vantive.

- Applications for knowledge management. Included in this category are a number of applications, such as data bases, archiving and imaging systems (from the SAP environment, mention may be made of the products from the house of IXOS), groupware, document management and workflow systems.

- Executive information systems. Executive information systems (EIS) are designed to support the management activities. Typically, EIS support planning and financial processes. These systems are designed to collect and to analyze both internal and external data. In most cases, EIS are built up on data warehouse applications. The functionality of EIS includes, for instance, drill down 
analyses, trend analyses, graphical processing of data and the special presentation of information.

\section{Summary and Outlook}

Starting from the business model of the information age, it has been the aim of this chapter to outline a business application architecture which has been derived from the business model of the information age. The example of the pharmaceutical branch has been used to illustrate these efforts. Two main elements of the application architecture are (1) the application areas where a total of 22 areas have been identified, and (2) the application components (see Figure 2) which are influenced by existing applications, such as master data management, ERP, DW, APS, EC, SFA, KM, and EIS systems.

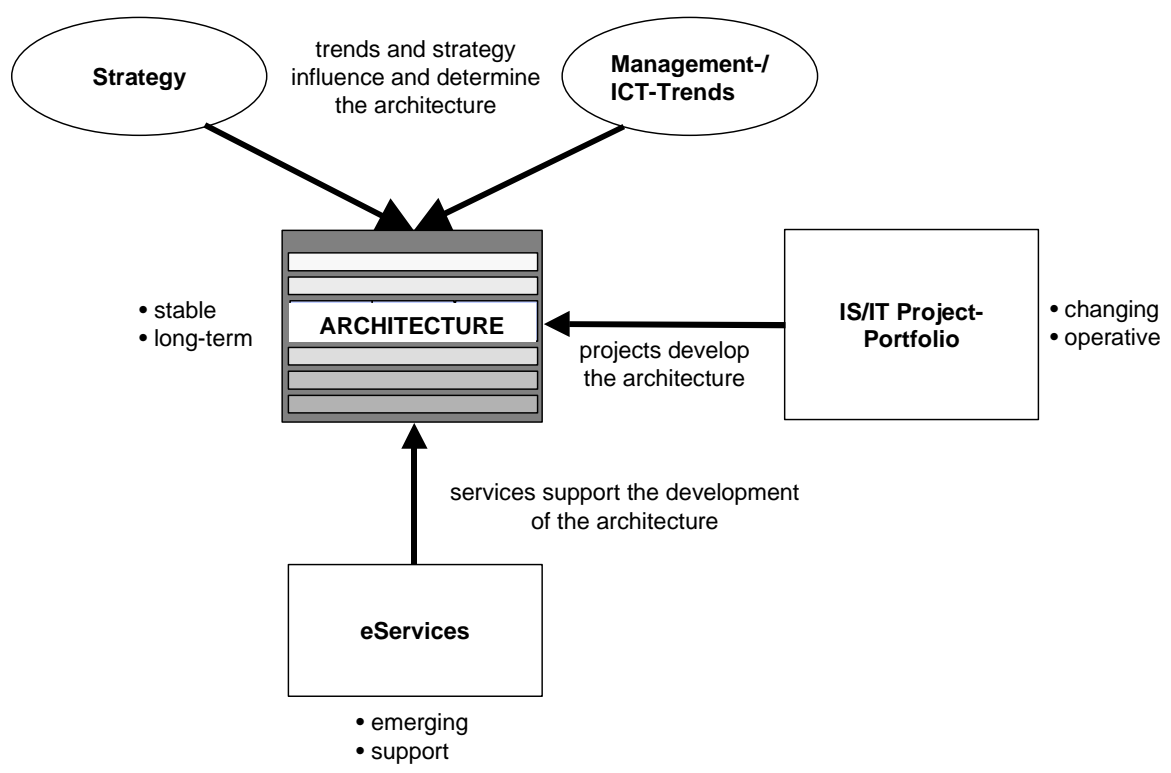

Figure 1: Application Architecture and IS/IT Project-Portfolio

In continuing this work it will be necessary to focus on the relations of the individual components of the architecture to each other. It will be necessary to analyze precisely which data are required to be exchanged between these components and what the requirements are that integration has to fulfil.

The real benefit of an application architecture for the enterprises of the information age is that it allows for a better coordination of different IT projects. In this process, the architecture blueprint will serve to establish a set of principles [cf. 
Metagroup 1998] for the IS/IT projects. Such a set of principles permits an evaluation of the specific projects to assess their relative importance in accomplishing the planned architecture. Another starting point for the continuation of the work is in the necessity to match the application architecture with the IT project portfolio of an enterprise. From the practical side of business, too, authors have stressed the need to analyze this aspect in greater depth and to match the application architecture with a company`s project portfolio and the available eServices (see Figure 1). 


\section{References}

[Alt et al. 2000]

Alt, R., Puschmann, T., Reichmayer, C., Strategies for Business Networking, in: Österle, H., Fleisch, E., Alt, R., Business Networking: Shaping Enterprise Relationships on the Internet, Springer, Berlin etc., 2000, pp. 95-116

[Bermudez/Girard 1997]

Bermudez, J., Girard, G., The Report on Supply Chain Management: i2 versus Manugistics, AMR Research, 1997

[Buxmann 1996]

Buxmann, P., Standardisierung betrieblicher Informationssysteme, Gabler, Wiesbaden, 1996

[Byrne 1998]

Byrne, J.A., The Corporation of the Future, in: Business Week, Special Ed. September 1998, The $21^{\text {st }}$ Century Economy, McGraw-Hill, New York, 1998

[Caves et al. 1990]

Caves, R.E., Frankel, J.A., Jones, R.W., World Trade and Payments, $5^{\text {th }}$ Ed., Scott, Foresman and Company, Glenview, 1990

[Fleisch/Österle 2000]

Fleisch, E., Österle, H., Business Networking: A Process-oriented Framework, in: Österle, H., Fleisch, E., Alt, R., Business Networking: Shaping Enterprise Relationships on the Internet, Springer, Berlin etc., 2000, pp. 55-91

[Jonsson 1998]

Jonsson, D., The Changing Requirements of Inter-Company Messaging, GE Information Services, Rockville etc., 1998

[Laszlo 1997]

Laszlo, E., Laszlo, C., Management Wissen der 3. Art, Gabler, Wiesbaden, 1997

[Metagroup 1997]

Metagroup, Enterprise Architecture Strategies: 'Best Practices' of Adaptive Systems, Metagroup, Stamford, 1997

[Metagroup 1998]

Metagroup, Enterprise Architecture Strategies: Adaptive Systems, The Role of Enterprisewide Technical Architecture, Metagroup, Stamford, 1998

[Millett 1997]

Millett, S., Battelle Forecasts, http://battelle.org/pr/drivers2.htm, 10.3.1997 
[Naisbitt 1994]

Naisbitt, J., Megatrends 2000 - Ten New Directions for the 1990s, Avon, New York, 1994

[Österle 1995]

Österle, H., Business in the Information Age: Heading for New Processes, Springer, Berlin etc., 1995

[Österle 2000]

Österle, H., Enterprise in the Information Age, in: Österle, H., Fleisch, E., Alt, R., Business Networking: Shaping Enterprise Relationships on the Internet, Springer, Berlin etc., 2000, pp. 17-54

[Porter 1992]

Porter, M.E., Competitive Strategy: Techniques for Analyzing Industries and Competitors, The Free Press, New York, 1992

[Ranadivé 1999]

Ranadivé, V., The Power of Now, McGraw-Hill, New York, 1999

[Sinz 1997]

Sinz, E.J., Architektur betrieblicher Informationssysteme, in: Rechenberger, P., Pomberger, G. (eds.), Handbuch der Informatik, Hanser, Munich, 1997

[Stein 1997a]

Stein, T., Orders From Chaos, in: Information Week (1997) 6, 1997

[Tibbetts 1995]

Tibbetts, K., Enterprise Architectures: A Comparison of Vendor Initiatives, IBM Corp., 1995, http:// www.software.ibm.com/openblue/kx95/cover.htm, 02.09.1998 